\title{
Annual Cost Burden by Level of Relapse Severity in Patients with Multiple Sclerosis
}

\author{
Jacqueline Nicholas · Huanxue Zhou · Chinmay Deshpande
}

Received: September 18, 2020 / Accepted: November 11, 2020 / Published online: November 27, 2020

(C) The Author(s) 2020

\section{ABSTRACT}

Introduction: The severity of relapses varies in multiple sclerosis (MS) and may lead to a differential cost burden. This study aimed to characterize the direct healthcare costs associated with relapses in patients with MS by the level of relapse severity.

Methods: This retrospective analysis used claims data extracted from the MarketScan ${ }^{\circledR}$ Databases from January 1, 2013 to March 31, 2017 (study period January 1, 2012 to March 31, 2018). Adult patients with at least one diagnosis of MS and 12 months of continuous enrollment prior to the first MS diagnosis to 12 months after the index date were included. On the basis of the severity of the relapse, patients were stratified into three cohorts: severe relapse (SR), mild/moderate relapse (MMR), and no relapse (NR). All-cause and MS-related costs were analyzed during the 12-month follow-up period. Group differences were assessed using descriptive and multivariate statistical analyses.

J. Nicholas

OhioHealth Multiple Sclerosis Center, Riverside

Methodist Hospital, Columbus, OH, USA

H. Zhou

KMK Consulting Inc., Morristown, NJ, USA

C. Deshpande $(\square)$

Novartis Pharmaceuticals Corporation, East

Hanover, NJ, USA

e-mail: chinmay.deshpande@novartis.com
Results: In total, 8775 patients with MS were analyzed: $6341(72 \%)$ in the NR cohort, 1929 (22\%) in the MMR cohort, and 505 (6\%) in the SR cohort. Overall, patients were mostly female (76\%), mean age was 50 years, and $25 \%$ were on a disease-modifying therapy. Mean (standard deviation [SD]) all-cause and MS-related costs among patients with a relapse were higher vs patients without a relapse (all-cause $\$ 66,489$ $[\$ 56,264]$ vs $\$ 41,494 \quad[\$ 48,417] ; \quad$ MS-related $\$ 48,700 \quad[\$ 43,364]$ vs $\$ 24,730 \quad[\$ 33,821])$. Among patients with a relapse, the mean (SD) all-cause costs were $\$ 87,979 \quad[\$ 65,991]$ vs $\$ 60,863[\$ 51,998]$ and MS-related costs were $\$ 69,586(\$ 51,187)$ vs $\$ 43,233 \quad[\$ 39,292]$ for patients in the SR vs MMR cohorts, respectively. A similar trend for increase in cost by relapse severity was observed in the adjusted analysis. Conclusion: Total annual all-cause and MS-related costs increased with severity of the relapses. High-efficacy treatments might reduce the severity of the relapses, thereby reducing the cost of care in patients with MS.

Keywords: Healthcare costs; Multiple sclerosis; Relapse; Severity 
Key Summary Points

Why carry out this study?

There is a need to better characterize total direct cost after the relapse in patients with MS using the most current data

\section{What did the study ask?}

The aim of this study was to evaluate annual cost of relapse by severity of relapse experienced by patients with MS

\section{What were the study outcomes/conclusions?}

Overall, this study highlights the cost burden incurred owing to MS relapses. The study provides a more accurate representation of cost burden of relapse (considered as occurrence of the event) using more recent data

\section{What was learned from the study?}

The study confirmed that the cost burden drastically increases with the severity of relapse. This underscores the need for high-efficacy therapies which can prevent relapse and progression in patients with multiple sclerosis

\section{DIGITAL FEATURES}

This article is published with digital features to facilitate understanding of the article. You can access the digital features on the article's associated Figshare page. To view digital features for this article go to https://doi.org/10.6084/m9. figshare.13214111.

\section{INTRODUCTION}

Multiple sclerosis (MS) is a chronic, debilitating neurological disease characterized by the emergence of new symptoms or worsening of existing symptoms leading to the accumulation of cognitive and neurological impairment. The prevalence of MS in the USA is estimated to be between 400,000 and 500,000, with most patients being female $[1,2]$. In relapsing-remitting MS (RRMS), episodes of neurological dysfunction are followed by periods of recovery. However, approximately $50 \%$ of relapses result in residual disability $[3,4]$, and over time, most patients will enter the secondary progressive phase [5] with a significant impact on the quality of life and an increasing economic burden [6]. High relapse activity in the first 2 years after the first diagnosis is predictive of time to sustained disability, early conversion to secondary progressive MS, and earlier mortality $[7,8]$.

The disease-modifying therapies (DMTs) were invented to reduce the relapse rates, delay disease progression, and reduce future disability in patients with RRMS [5, 9]. However, switching among the first-line DMTs is common and is an important predictor of economic burden in patients with MS $[10,11]$. Moreover, the use of high-efficacy (and costly) DMTs could prevent relapses and delay disease progression leading to savings in overall costs $[12,13]$.

Variation in the intensity of a relapse can lead to different clinical and financial burdens [14-16]. A study in 2002 estimated that the typical costs were $\$ 12,870$ per high-intensity episode of relapse, $\$ 1847$ per moderate-intensity episode of relapse, and $\$ 243$ per mild-intensity episode of relapse [14]. A study by Parise et al. in 2012 estimated that the annual direct healthcare costs were higher for patients with an MS relapse. The incremental annual direct costs attributable to relapses (vs no relapse) were $\$ 8269$ for patients with moderate-severity relapses and $\$ 24,180$ for patients with highseverity relapses [16]. Parise et al. estimated the cost burden after the first diagnosis of MS (index date) [16]; thus, characterization of the cost burden incurred after a relapse may have been missed. To address this gap, the present study estimated the cost burden after a relapse event (i.e., the index date was the date of the most severe occurrence of a relapse) using more recent data to provide true characterization of the cost of relapses by severity. 
Analogous to the study by Parise et al., the present study sought to (a) measure the costs after a relapse event and (b) estimate the healthcare utilization and costs associated with a relapse, stratified by relapse severity, using most recent data.

\section{METHODS}

\section{Study Design and Data Source}

This was a retrospective, observational analysis of the claims data retrieved from the Truven Health Analytics MarketScan ${ }^{\circledR}$ Commercial Claims and Encounters (Commercial Database) and Medicare Supplemental and Coordination of Benefits databases (Fig. 1) [17]. The Commercial Database is a nationally representative database of the US population with employersponsored insurance data from more than 100 large employers and health plans, accounting for approximately 40 million members across the USA aged 0-64 years. The Medicare Supplemental database is nationally representative of the Medicare population with supplemental insurance. This includes data from employersponsored Medicare supplemental plans, accounting for approximately 3 million beneficiaries in the USA aged at least 65 years and eligible Medicare beneficiaries aged less than 65 years.

This study complied with all applicable laws, regulations, and guidance regarding patient protection, including patient privacy. All study data were accessed using techniques compliant with the Health Insurance Portability and Accountability Act (HIPAA) of 1996, and no identifiable or protected health information was extracted during the course of the study. Thus, the study did not require informed consent or institutional review board approval. The original de-identified data used in this retrospective analysis was obtained from and are the property of Truven Health Analytics (now IBM Watson Health). The raw data were provided by Truven/ IBM and were used to create the analytical files for the study.

\section{Patient Selection}

Adult patients (aged at least 18 years) newly diagnosed with MS [International Classification of Diseases, Ninth/Tenth Revision, Clinical Modification (ICD-9/10-CM) code 340/G35] and having at least two non-rule-out diagnoses of MS were included. Data used in this study

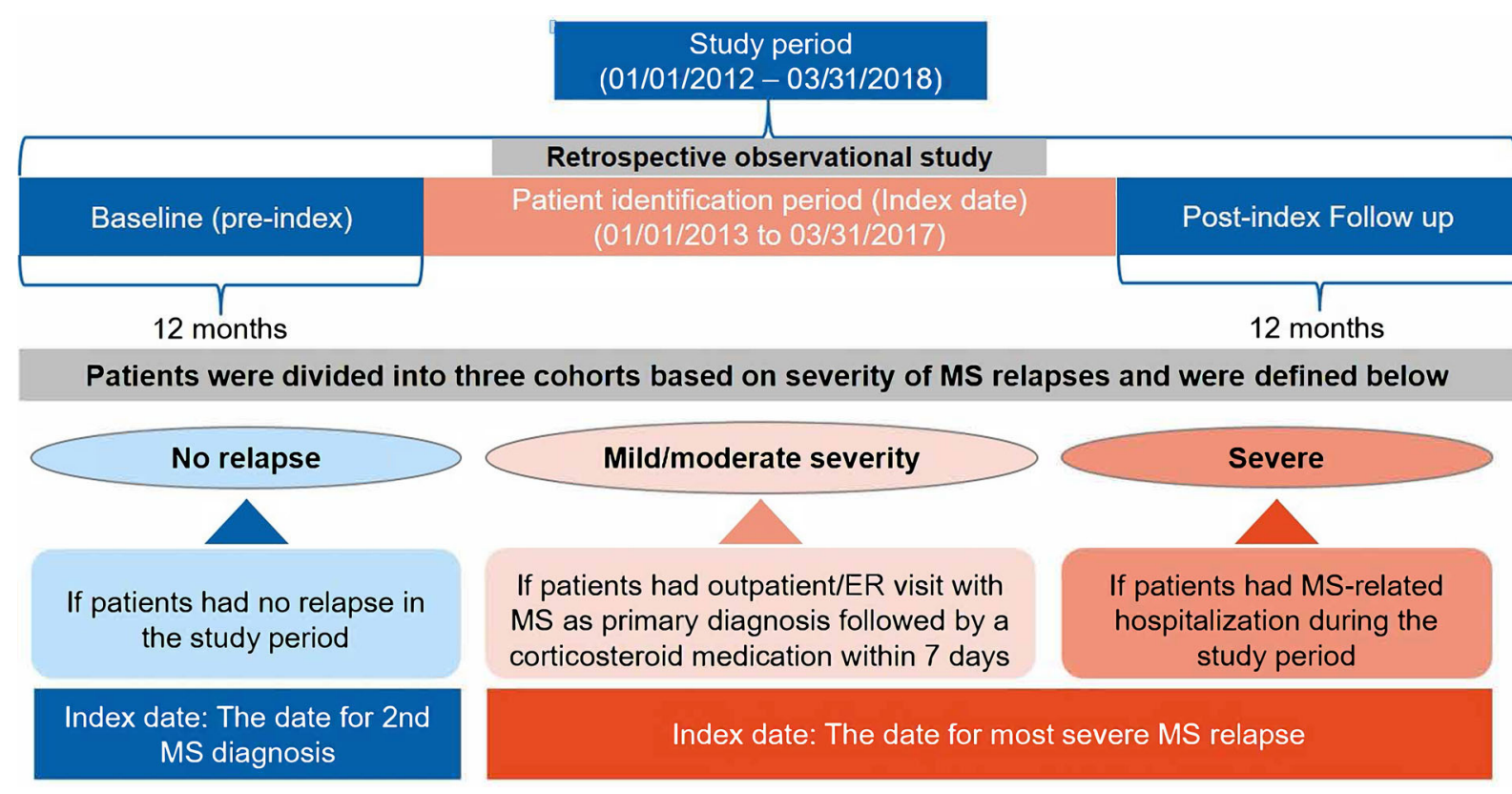

Fig. 1 Study design. ER emergency room, $M S$ multiple sclerosis 
spanned over the period from January 1, 2012 to March 31, 2018 (study period). All patients were identified between January 1, 2013 and March 31, 2017 (identification period). The date of the first claim for MS diagnosis was termed as the first diagnosis date. All patients having continuous enrollment with medical and pharmacy coverages for 12 months prior to the first MS diagnosis (baseline period) to 12 months after the index date (follow-up period) were included in this analysis. For patients with an MS relapse, the date of the occurrence of the most severe relapse between January 1, 2013 and March 31, 2017 was considered as the index date. For patients who did not have relapses, the index date was the second non-rule-out MS diagnosis date for the characterization of costs. Patients aged less than 18 years, affected by catastrophic events, who underwent organ transplant, who were diagnosed with cancer, or who were diagnosed with MS in the 1 year prior to the first MS diagnosis date were excluded (Fig. 2).

Eligible patients were classified into three mutually exclusive cohorts based on the severity of the MS relapse [18]:

(a) Severe relapse (SR) cohort: patients who had hospitalization with MS as the primary diagnosis

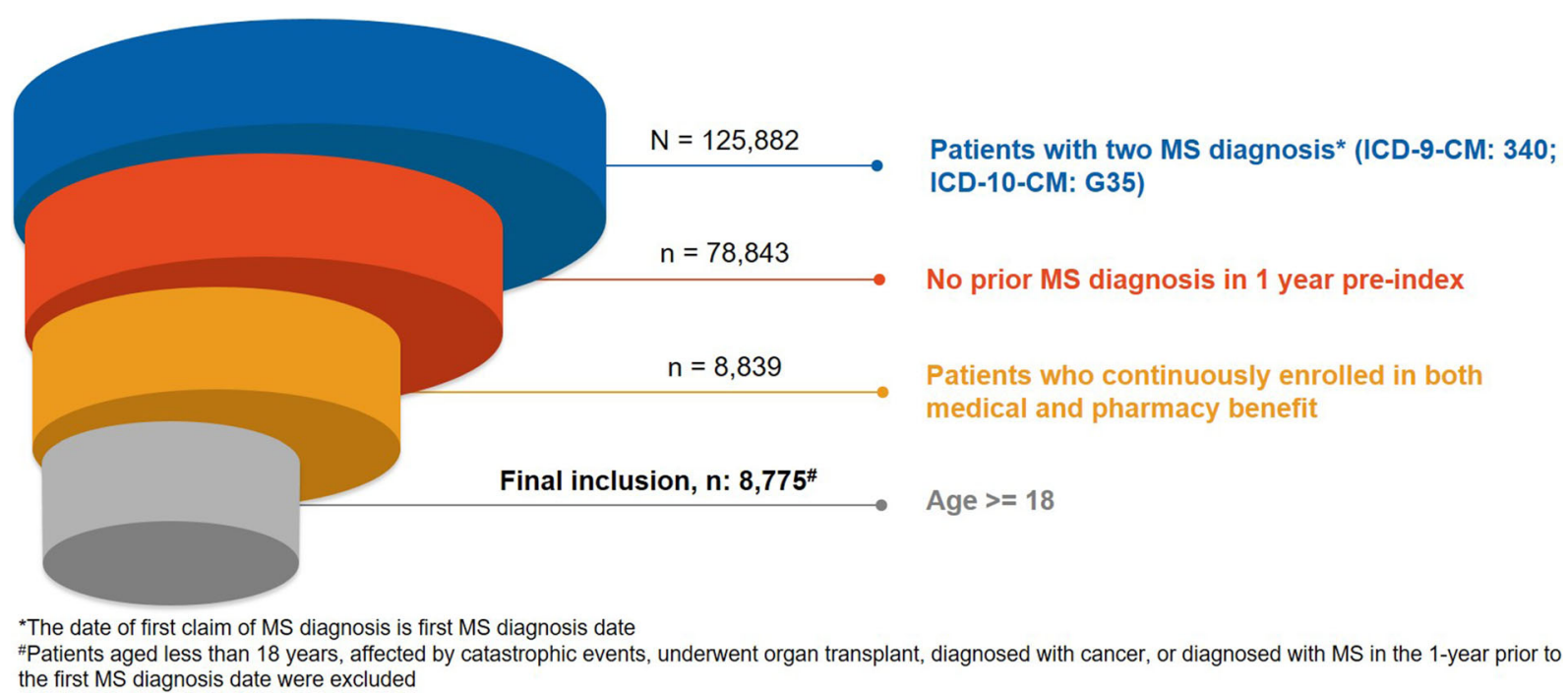

Fig. 2 Patient flow. $C M$ clinical modification, $I C D$ International Classification of Diseases, $M S$ multiple sclerosis (b) Mild/moderate relapse (MMR) cohort: patients with an MS diagnosis at any position and who had outpatient or emergency room (ER) visits with MS as the primary diagnosis followed by the use of a corticosteroid medication within 7 days

(c) No relapse (NR) cohort: patients who had no relapse during the study period.

\section{Study Outcomes}

The all-cause and MS-related costs in the 12-month follow-up period for each of the three severity cohorts were estimated. Total all-cause costs included all medical costs (inpatient, outpatient, and ER) and pharmacy costs paid by the patient and the payer.

MS-related costs included all medical costs and pharmacy costs incurred for MS. MS-related pharmacy costs included costs for diseasemodifying therapies (DMTs) approved for MS (e.g., teriflunomide [19], interferon beta-1a $[20,21]$, interferon beta-1b $[22,23]$, fingolimod [24], natalizumab [25], glatiramer acetate [26], and alemtuzumab [27]). 


\section{Statistical Analysis}

Patient demographic and disease characteristics were summarized for each cohort and quantified as counts and percentages for categorical variables and as means and standard deviations (SDs) for continuous variables. Mean (SD) and median (interquartile range) were reported for total all-cause healthcare costs. Differences between cohorts for each variable were tested using Wilcoxon-Mann-Whitney test for continuous variables. A multivariable generalized linear model with gamma distribution was used to estimate all-cause and MS-related costs by controlling for demographic characteristics (age, sex, year of the index date, region) and insurance coverage $[16,28]$. Three-cluster severity cohorts were included in the model to estimate the cost for each cohort by the level of severity. All analyses were performed using SAS version 9.4 (SAS Institute, Cary, NC, USA).

\section{RESULTS}

\section{Patient Population}

The final study sample included 8775 patients with MS. Of these, 6341 (72\%) experienced no relapse (NR cohort), 1929 (22\%) experienced a mild/moderate relapse (MMR cohort), and the remaining $505 \quad(6 \%)$ experienced a severe relapse (SR cohort) (Fig. 2). In total, 2434 patients experienced a relapse, and $20.75 \%$ of these patients experienced a severe relapse.

\section{Patient Characteristics}

Baseline demographic and clinical characteristics stratified by cohort are presented in Table 1. In the overall cohort $(N=8775)$, the mean (SD) age of the patients was 49.9 (12.8) years and $75.7 \%$ were female. Patients in the SR cohort had a mean age of 44.2 years. Most patients across the three cohorts were aged from 45 to 54 years. Within the US geographic region, $36.8 \%$ of patients lived in the South, $26.7 \%$ in the North Central, $21.3 \%$ in the Northeast, and $14.9 \%$ in the West. The distributions of sex, plan type, and health insurance type were largely similar across cohorts (Table 1).

\section{All-Cause Costs}

The mean (SD) total cost per patient for the overall MS cohort was \$48,427 $(\$ 51,932)$ (Table 2). On the basis of the unadjusted analysis, the cost per MS patient with a relapse was significantly higher than the cost per MS patient without a relapse $(\$ 66,489[\$ 56,264]$ vs $\$ 41,494$ [\$48,417]; mean difference [95\% confidence interval; CI] \$24,995 [\$22,461-27,529], $P<0.0001)$. After baseline demographic covariates were controlling for, the mean difference (CI) was $\$ 24,300 \quad(\$ 21,613-27,207)$ between patients with and without a relapse (Table 3). On the evaluation of individual relapse severity-based cohorts among patients with a relapse, the mean (SD) unadjusted allcause cost incurred per patient in the MMR and SR cohorts was $\$ 60,863(\$ 51,998)$ and $\$ 87,979$ $(\$ 65,991)$, respectively (Table 2$)$. Similar mean (SD) all-caused costs were obtained from the adjusted analysis (MMR \$60,594 [\$1277]; SR $\$ 86,749$ [\$3044]) (Table 3).

Pharmacy costs were the main drivers for overall costs in the NR (amounting to $56.5 \%$ vs medical costs $43.5 \%)$ and MMR $(62.4 \%$ vs medical costs $37.6 \%$ ) cohorts. In contrast, incremental costs in the SR cohort were driven by higher medical costs (pharmacy costs $44.7 \%$ vs medical costs 55.3\%) (Table 2). Among patients who had experienced a relapse, 21\% were from the SR cohort and accounted for a total of $27 \%$ of the cost burden owing to relapse.

\section{MS-Related Costs}

The mean (SD) annual MS-related cost for a patient with MS was $\$ 31,379(\$ 38,251)$. In the unadjusted analysis, the mean (SD) MS-related cost incurred by patients with no relapse vs those with a relapse was $\$ 24,730(\$ 33,821)$ vs $\$ 48,700(\$ 43,364)$, respectively. A similar trend with an incremental mean difference (CI) of $\$ 21,314(\$ 19,405-23,204)$ was found among the two cohorts (NR vs those with relapse) in the adjusted analysis (Tables 2, 3). The unadjusted mean (SD) cost across specific severity cohorts 
Table 1 Baseline characteristics for overall cohort and by relapse severity

\begin{tabular}{|c|c|c|c|c|}
\hline & Overall $(N=8775)$ & $\mathrm{NR}(n=6341)$ & $\operatorname{MMR}(n=1929)$ & $\operatorname{SR}(n=505)$ \\
\hline Age, years, mean (SD) & $49.9(12.8)$ & $50.9(12.8)$ & $47.9(11.9)$ & $44.2(12.8)$ \\
\hline \multicolumn{5}{|l|}{ Age group, years, $n$ (\%) } \\
\hline $18-34$ & $1001(11.4)$ & $634(10)$ & $244(12.6)$ & $123(24.4)$ \\
\hline $35-44$ & $1858(21.2)$ & $1237(19.5)$ & $497(25.8)$ & $124(24.6)$ \\
\hline $45-54$ & $2746(31.3)$ & $1977(31.2)$ & $627(32.5)$ & $142(28.1)$ \\
\hline $55-64$ & $2297(26.2)$ & $1768(27.9)$ & $434(22.5)$ & $95(18.8)$ \\
\hline $65-79$ & $716(8.2)$ & $585(9.2)$ & $112(5.8)$ & $19(3.8)$ \\
\hline $80+$ & $157(1.8)$ & $140(2.2)$ & $15(0.8)$ & $2(0.4)$ \\
\hline Female, $n(\%)$ & $6642(75.7)$ & $4789(75.5)$ & $1473(76.4)$ & $380(75.2)$ \\
\hline CCI, mean (SD) & $0.63(1.3)$ & $0.63(1.3)$ & $0.62(1.2)$ & $0.60(1.1)$ \\
\hline MS symptoms, $n(\%)$ & $5288(60.3)$ & $3672(57.9)$ & $1267(65.7)$ & $349(69.1)$ \\
\hline \multicolumn{5}{|l|}{ Region, $n$ (\%) } \\
\hline Northeast & $1870(21.3)$ & $1407(22.2)$ & $353(18.3)$ & $110(21.8)$ \\
\hline North Central & $2341(26.7)$ & $1706(26.9)$ & $504(26.1)$ & $131(25.9)$ \\
\hline South & $3229(36.8)$ & $2223(35.1)$ & $794(41.2)$ & $212(42)$ \\
\hline West & $1309(14.9)$ & $983(15.5)$ & $274(14.2)$ & $52(10.3)$ \\
\hline Unknown & $26(0.3)$ & $22(0.3)$ & $4(0.2)$ & $0(0)$ \\
\hline \multicolumn{5}{|l|}{ Plan type, $n(\%)$} \\
\hline Fee for service & $7602(86.6)$ & $5498(86.7)$ & $1678(87)$ & $426(84.4)$ \\
\hline HMO and POS capitation & $1080(12.3)$ & $768(12.1)$ & $235(12.2)$ & $77(15.2)$ \\
\hline Unknown & $93(1.1)$ & $75(1.2)$ & $16(0.8)$ & $2(0.4)$ \\
\hline \multicolumn{5}{|l|}{ Insurance type, $n$ (\%) } \\
\hline Commercial & $7860(89.6)$ & $5573(87.9)$ & $1806(93.6)$ & $481(95.2)$ \\
\hline Medicare supplemental & $915(10.4)$ & $768(12.1)$ & $123(6.4)$ & $24(4.8)$ \\
\hline
\end{tabular}

CCI Charlson Comorbidity Index, HMO health maintenance organization, $M M R$ mild/moderate relapse, $M S$ multiple sclerosis, $N R$ no relapse, $P O S$ point of service, $S D$ standard deviation, $S R$ severe relapse

was $\$ 43,233(\$ 39,292)$ in the MMR cohort and $\$ 69,586(\$ 51,187)$ in the SR cohort. The adjusted mean (SD) annual cost per patient was $\$ 26,021(\$ 460), \$ 42,457(\$ 910)$, and $\$ 65,970$ (\$2458) for patients in the NR, MMR, and SR cohorts, respectively (Table 3 ).

\section{DISCUSSION}

In this US retrospective analysis, using a similar but more targeted methodology to characterize the true cost after the occurrence of a relapse event and with more contemporary data, we evaluated the direct healthcare costs associated with MS, stratified by relapse occurrence and severity, to highlight the current burden of 


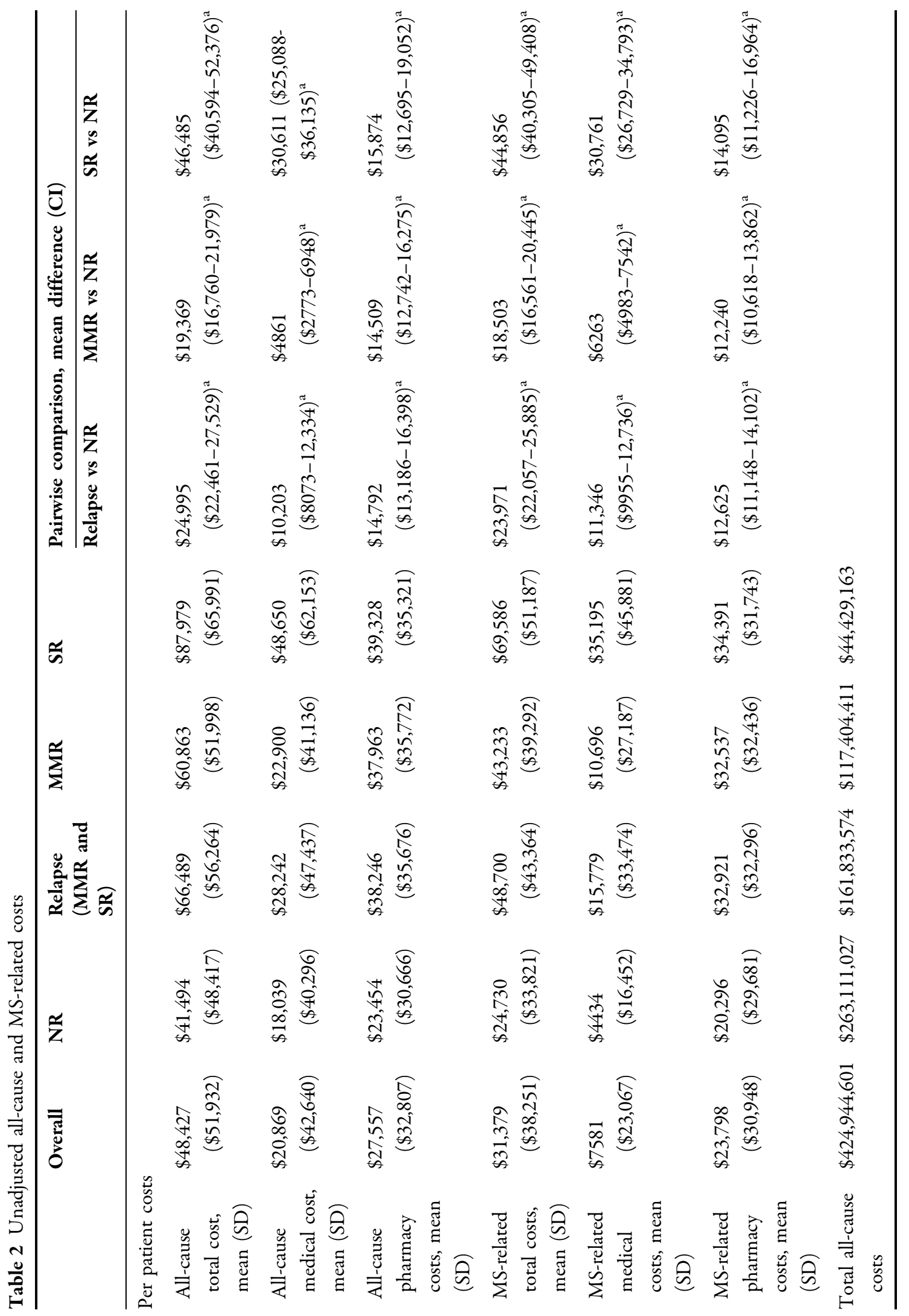




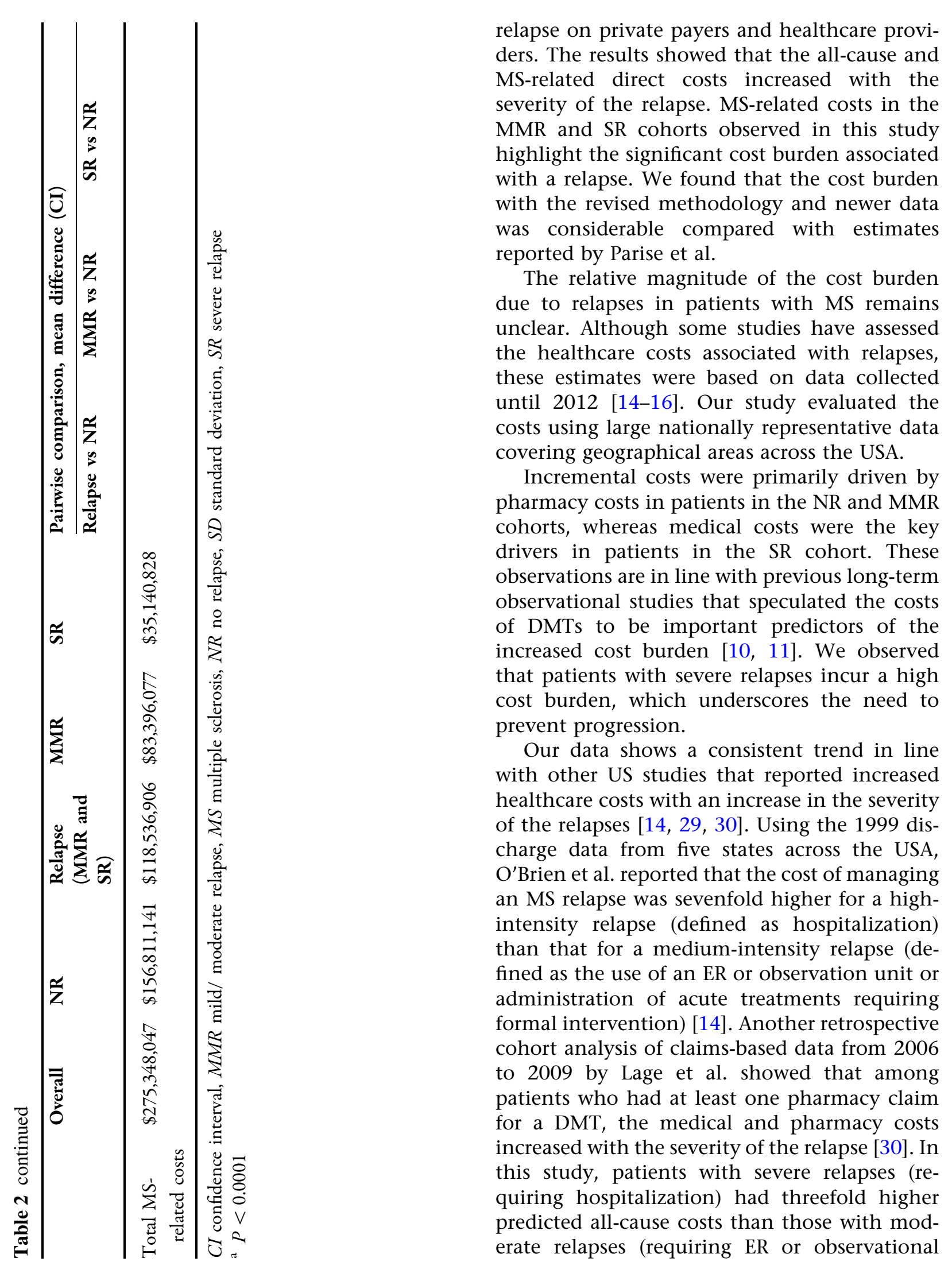




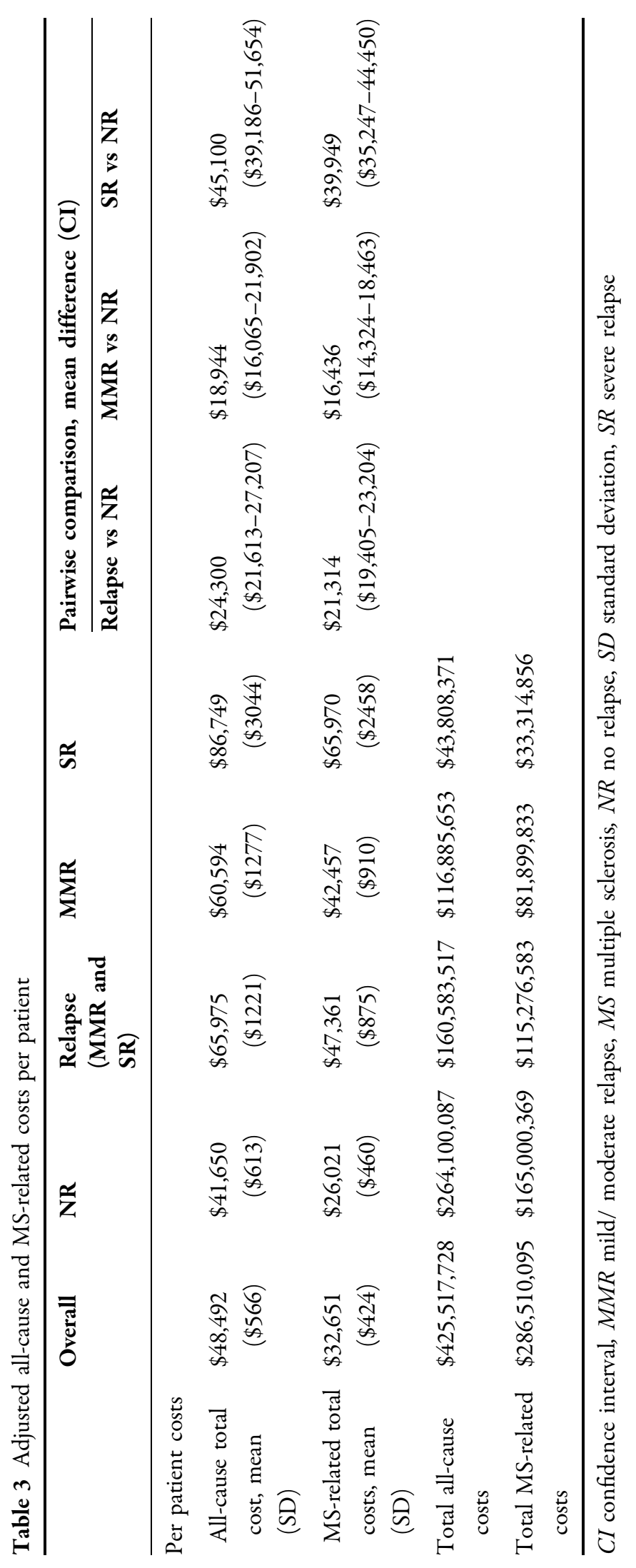


unit or administration of acute treatments requiring formal intervention) [30].

Evidence from several cross-sectional studies has demonstrated cost differences between patients with a relapse and those without a relapse [17, 31-37]. Another survey-based international study (TRIBUNE) highlighted that cost per patient per year was higher for patients with RRMS and moderate and severe relapses than for those without a relapse [6, 38, 39]. A USA-based claims study reported that high relapse activity was associated with greater resource utilization vs non-high relapse activity and thus higher costs [40]. Analysis of patients with and without a high frequency of relapse activity found greater resource utilization and costs among patients with higher relapse activity (defined as two or more relapses per year) than in patients without high relapse activity. Mean total all-cause non-DMT costs were $\$ 12,057$ higher in patients with a high frequency of relapse compared with those in patients without a high frequency of relapse [40]. Similarly, the current analysis reported $\$ 10,203$ higher all-cause medical costs (nonpharmacy costs) incurred by patients with moderate to severe relapses vs patients with no relapses.

Analogous to the USA-based studies, several studies from other countries have also characterized healthcare costs related to MS relapses [11, 15, 41, 42]. A retrospective study of patients with MS followed for over 10 years found that among patients using DMTs, the overall annual direct costs were associated with the annualized relapse rate [11]. A 10\% increase in healthcare costs was associated with a $1 \%$ reduction in conversion to secondary progressive MS [11]. The analysis of claims-based data from Japan that included patients with newly diagnosed MS showed that the frequency of relapses and per patient per month medical costs were directly correlated [42]. Similar findings were reported from other studies [15, 29, 41, 43]. Evidence from a recent systematic review suggests that early treatment with high-efficacy DMTs offers improved control of relapse activity compared with delayed therapy [44]. Overall, the findings of these studies extend support to the current study and highlight the importance of patient management strategies and treatments aimed at reducing the frequency of MS relapses in a US commercial population.

The current analysis has several limitations. There are potential inaccuracies or omissions in the classification of MS, covariates, and outcomes as the data were identified from claims databases as opposed to medical records. Given that the MarketScan ${ }^{\circledR}$ database does not contain data regarding the severity of the relapse, the severity of the relapse was defined by the treatment setting (hospital, ER, outpatient clinic) and may not reflect the true severity of the relapse. Mild relapses or relapses of short duration that usually do not affect the activities of daily living and therefore do not require a corticosteroid therapy or hospitalization were less likely to be considered in the present analysis. However, we have identified MS relapses using a validated medical chart review algorithm, and should therefore less likely alter our conclusions [18]. While differences across cohorts were adjusted using a generalized linear regression model, systematic differences could exist across the study cohorts because of unknown confounders [45]. Another limitation of this study is that the costs were not adjusted for inflation. However, we acknowledge that the cost burden after adjusting for inflation might be higher. Finally, despite the size of and inclusion of enrollees from across all US states in the MarketScan ${ }^{\circledR}$ database, the database neither completely represents the entire private insurance market or general US population nor includes individuals outside of the USA, but it is one of the largest databases representing the commercial population in the USA. These limitations may affect the generalizability of the study findings.

\section{CONCLUSIONS}

The results from this real-world study demonstrate that all-cause and MS-related direct costs increased with the severity of the relapse. One in five relapses is severe and leads to a high cost burden. While pharmacy costs were the primary drivers among patients in the NR and MMR 
cohorts, medical costs were the key cost drivers in patients in the SR cohort.

Overall, this study highlights the cost burden incurred owing to MS relapses. The study provides a more accurate representation of cost burden of relapse (considered as occurrence of the event) using more recent data. The finding that the cost burden drastically increases with the level of severity underscores the need for preventing progression and relapse via optimal treatments.

\section{ACKNOWLEDGEMENTS}

Funding. Funding for this study including the journal's Paid Service and Open Access fees was provided by Novartis Pharmaceuticals Corporation, East Hanover, NJ, USA.

Authorship. All named authors meet the International Committee of Medical Journal Editors (ICMJE) criteria for authorship for this article, take responsibility for the integrity of the work as a whole, and have given their approval for this version to be published.

Author contributions. Chinmay Deshpande and Jacqueline Nicholas were responsible for the conceptualization of the study. Huanxue Zhou helped in the execution and analyses. All authors contributed to the interpretation of the results and manuscript development.

Medical Writing, Editorial, and Other Assistance. Michelle Adams (Write All, Inc., of Sonoma, CA), Vijayalakshmi Vasanthaprasad (Novartis Healthcare Pvt Ltd, Hyderabad), and Lohit Badgujar (Novartis Healthcare Pvt Ltd, Hyderabad) provided medical writing and editorial assistance for this manuscript. Novartis Pharmaceuticals Corporation, East Hanover, NJ, USA, funded the editorial/writing assistance services.

Disclosures. Jacqueline Nicholas, MD, MPH, works at the OhioHealth Multiple Sclerosis Center, Riverside Methodist Hospital in Columbus, Ohio, and serves as a consultant for
Novartis Pharmaceuticals Corporation, Biogen, Idec Corporation, Bristol Myers Squibb, EMD Serono, Genzyme Corporation, Genentech, Siegal Rare Neuroimmune Association, National MS Society, and Multiple Sclerosis Association of America. She has research grants from Novartis Pharmaceuticals Corporation, Adamas, Alexion, Biogen, Idec Corporation, Genzyme Corporation, and PCORI. She serves on the speakers bureau for Biogen, Bristol Myers Squibb, EMD Serono, Genentech, Novartis and Vielo Bio. Huanxue Zhou is an employee of KMK consulting Inc., Morristown, NJ, USA, and is a consultant for Novartis Pharmaceuticals Corporation. Chinmay Deshpande is an employee of Novartis Pharmaceuticals Corporation, East Hanover, NJ, USA.

Prior Presentation. Data were previously presented at the Academy of Managed Care Pharmacy (AMCP) Nexus 2019, National Harbor, Maryland, USA, October 29-November 1, 2019.

Compliance with Ethics Guidelines. This study complied with all applicable laws, regulations, and guidance regarding patient protection, including patient privacy. All study data were accessed using techniques compliant with the Health Insurance Portability and Accountability Act (HIPAA) of 1996, and no identifiable or protected health information was extracted during the course of the study. Thus, the study did not require informed consent or institutional review board approval.

Data Availability. The original de-identified data used in this retrospective analysis was obtained from and are the property of Truven Health Analytics (now IBM Watson Health). The raw data were provided by Truven/IBM and were used to create the analytical files for the study. If any researcher requires access to the analytical files that were derived from the MarketScan ${ }^{\circledR}$ database, a third-party use agreement must be executed by the third party, Novartis, and Truven/IBM, and access fees may apply. Any third party desiring access to the raw data that were used to generate the analytical files should contact Truven/IBM directly regarding 
the possibility of licensing the data for the appropriate license fees. The datasets generated during and/or analyzed during the current study are presented in the manuscript.

Open Access. This article is licensed under a Creative Commons Attribution-NonCommercial 4.0 International License, which permits any non-commercial use, sharing, adaptation, distribution and reproduction in any medium or format, as long as you give appropriate credit to the original author(s) and the source, provide a link to the Creative Commons licence, and indicate if changes were made. The images or other third party material in this article are included in the article's Creative Commons licence, unless indicated otherwise in a credit line to the material. If material is not included in the article's Creative Commons licence and your intended use is not permitted by statutory regulation or exceeds the permitted use, you will need to obtain permission directly from the copyright holder. To view a copy of this licence, visit http://creativecommons.org/licenses/by$\mathrm{nc} / 4.0 /$.

\section{REFERENCES}

1. GBD 2016 Multiple Sclerosis Collaborators. Global, regional, and national burden of multiple sclerosis 1990-2016: a systematic analysis for the global burden of disease study 2016. Lancet Neurol. 2019;18:269-85.

2. Dilokthornsakul P, Valuck RJ, Nair KV, Corboy JR, Allen RR, Campbell JD. Multiple sclerosis prevalence in the United States commercially insured population. Neurol. 2016;86:1014-21.

3. Hirst C, Ingram G, Pearson O, Pickersgill T, Scolding $\mathrm{N}$, Robertson N. Contribution of relapses to disability in multiple sclerosis. J Neurol. 2008;255: 280-7.

4. Lublin FD, Baier M, Cutter G. Effect of relapses on development of residual deficit in multiple sclerosis. Neurol. 2003;61:1528-32.

5. Confavreux C, Vukusic S, Moreau T, Adeleine P. Relapses and progression of disability in multiple sclerosis. N Engl J Med. 2000;343:1430-8.
6. Karampampa K, Gustavsson A, Miltenburger C, Kindundu CM, Selchen DH. Treatment experience, burden, and unmet needs (TRIBUNE) in multiple sclerosis: the costs and utilities of MS patients in Canada. J Popul Ther Clin Pharmacol. 2012;19:e1125.

7. Leray E, Yaouanq J, Le Page E, et al. Evidence for a two-stage disability progression in multiple sclerosis. Brain. 2010;133:1900-13.

8. Scalfari A, Neuhaus A, Daumer M, Muraro PA, Ebers GC. Onset of secondary progressive phase and longterm evolution of multiple sclerosis. J Neurol Neurosurg Psychiatry. 2014;85:67-75.

9. Kremenchutzky M, Rice GP, Baskerville J, Wingerchuk DM, Ebers GC. The natural history of multiple sclerosis: a geographically based study 9: observations on the progressive phase of the disease. Brain. 2006;129:584-94.

10. Moccia M, Loperto I, Lanzillo R, et al. Persistence, adherence, healthcare resource utilisation and costs for interferon beta in multiple sclerosis: a population-based study in the Campania region (southern Italy). BMC Health Serv Res. 2020;20:797.

11. Moccia M, Palladino R, Lanzillo R, et al. Healthcare costs for treating relapsing multiple sclerosis and the risk of progression: a retrospective Italian cohort study from 2001 to 2015. PLoS One. 2017;12:e0169489.

12. Owens GM, Olvey EL, Skrepnek GH, Pill MW. Perspectives for managed care organizations on the burden of multiple sclerosis and the cost-benefits of disease-modifying therapies. J Manag Care Pharm. 2013;19:S41-53.

13. Owens GM. Economic burden of multiple sclerosis and the role of managed care organizations in multiple sclerosis management. Am J Manag Care. 2016;22:S151-8.

14. O'Brien JA, Ward AJ, Patrick AR, Caro J. Cost of managing an episode of relapse in multiple sclerosis in the United States. BMC Health Serv Res. 2003;3: 17.

15. O'Connell K, Kelly SB, Fogarty E, et al. Economic costs associated with an MS relapse. Mult Scler Relat Disord. 2014;3:678-83.

16. Parise H, Laliberte F, Lefebvre $P$, et al. Direct and indirect cost burden associated with multiple sclerosis relapses: excess costs of persons with MS and their spouse caregivers. J Neurol Sci. 2013;330:71-7.

17. Jones E, Pike J, Marshall T, Ye X. Quantifying the relationship between increased disability and health care resource utilization, quality of life, work 
productivity, health care costs in patients with multiple sclerosis in the US. BMC Health Serv Res. 2016;16:294.

18. Chastek BJ, Oleen-Burkey M, Lopez-Bresnahan MV. Medical chart validation of an algorithm for identifying multiple sclerosis relapse in healthcare claims. J Med Econ. 2010;13:618-25.

19. Genzyme. AUBAGIO (teriflunomide) tablets, for oral use. Prescribing information. 2016. https:// www.accessdata.fda.gov/drugsatfda_docs/label/ 2016/202992s002lbl.pdf. Accessed Nov 2016.

20. Biogen. AVOneX (interferon beta-1a) injection, for intramuscular injection. Prescribing information. 2016. https://www.avonex.com/content/dam/ commercial/multiple-sclerosis/avonex/pat/en_us/ pdf/Avonex_Prescribing_Information.pdf. Accessed Mar 2016.

21. EMD Serono. REBIF (interferon beta-1a), for subcutaneous injection. Prescription information. 2015. https://www.emdserono.com/content/dam/web/ corporate/non-images/country-specifics/us/pi/ rebif-pi.pdf. Accessed Nov 2015.

22. Bayer Health Care. BETASERON (interferon beta-1b) for injection, for subcutaneous use. Prescribing information. 2016. http://labeling.bayerhealthcare. com/html/products/pi/Betaseron_PI.pdf. Accessed Mar 2017.

23. Novartis. EXTAVIA (interferon beta-1b) for injection, for subcutaneous use. Prescribing information. 2018. https://www.accessdata.fda.gov/ drugsatfda_docs/label/2018/125290s066lbl.pdf. Accessed Dec 2018.

24. Novartis. GILENYA (fingolimod) capsules, for oral use. Prescribing information. 2016. https://www. pharma.us.novartis.com/sites/www.pharma.us. novartis.com/files/gilenya.pdf. Accessed Mar 2017.

25. Biogen. TYSABRI (natalizumab) injection, for intravenous use. Prescribing information. 2018. https://www.accessdata.fda.gov/drugsatfda_docs/ label/2018/125104s960s963lbl.pdf. Accessed Apr 2018.

26. Teva Neuroscience. Copaxone (glatiramer acetate injection) for subcutaneous use. Prescribing information. 2018. https://www.accessdata.fda.gov/ drugsatfda_docs/label/2018/020622s104lbl.pdf. Accessed Sep 2018.

27. Genzyme. LEMTRADA (alemtuzumab) injection, for intravenous use. Prescribing information. 2016. http://products.sanofi.us/lemtrada/lemtrada.pdf. Accessed Aug 2017.
28. Moccia M, Tajani A, Acampora R, et al. Healthcare resource utilization and costs for multiple sclerosis management in the Campania region of Italy: comparison between centre-based and local service healthcare delivery. PLoS One. 2019;14:e0222012.

29. Ivanova JI, Bergman RE, Birnbaum HG, Phillips AL, Stewart M, Meletiche DM. Impact of medication adherence to disease-modifying drugs on severe relapse, and direct and indirect costs among employees with multiple sclerosis in the US. J Med Econ. 2012;15:601-9.

30. Lage MJ, Carroll CA, Fairman KA. Using observational analysis of multiple sclerosis relapse to design outcomes-based contracts for disease-modifying drugs: a feasibility assessment. J Med Econ. 2013;16: 1146-53.

31. Oleen-Burkey M, Castelli-Haley J, Lage MJ, Johnson KP. Burden of a multiple sclerosis relapse: the patient's perspective. Patient. 2012;5:57-69.

32. Lebrun-Frenay C, Kobelt G, Berg J, Capsa D, Gannedahl M, Sclerosis EM. New insights into the burden and costs of multiple sclerosis in Europe: results for France. Mult Scler J. 2017;23:65-77.

33. Flachenecker P, Kobelt G, Berg J, Capsa D, Gannedahl M, Sclerosis EM. New insights into the burden and costs of multiple sclerosis in Europe: results for Germany. Mult Scler J. 2017;23:78-90.

34. Battaglia M, Kobelt G, Ponzio M, et al. New insights into the burden and costs of multiple sclerosis in Europe: results for Italy. Mult Scler J. 2017;23: 104-16.

35. Oreja-Guevara C, Kobelt G, Berg J, Capsa D, Eriksson J, Sclerosis EM. New insights into the burden and costs of multiple sclerosis in Europe: results for Spain. Mult Scler J. 2017;23:166-78.

36. Thompson A, Kobelt G, Berg J, et al. New insights into the burden and costs of multiple sclerosis in Europe: results for the United Kingdom. Mult Scler J. 2017;23:204-16.

37. Kobelt G, Thompson A, Berg J, et al. New insights into the burden and costs of multiple sclerosis in Europe. Mult Scler J. 2017;23:1123-36.

38. Karampampa K, Gustavsson A, van Munster ET, et al. Treatment experience, burden, and unmet needs (TRIBUNE) in Multiple Sclerosis study: the costs and utilities of MS patients in the Netherlands. J Med Econ. 2013;16:939-50.

39. Karabudak R, Karampampa K, Caliskan Z, Group TS. Treatment experience, burden and unmet needs (TRIBUNE) in MS study: results from Turkey. J Med Econ. 2015;18:69-75. 
40. Raimundo K, Tian H, Zhou H, et al. Resource utilization, costs and treatment patterns of switching and discontinuing treatment of MS patients with high relapse activity. BMC Health Serv Res. 2013;13:131.

41. Hawton AJ, Green C. Multiple sclerosis: relapses, resource use, and costs. Eur J Health Econ. 2016;17: 875-84.

42. Ogino M, Kawachi I, Otake K, et al. Current treatment status and medical cost for multiple sclerosis based on analysis of a Japanese claims database. Clin Exp Neuroimmunol. 2016;7:158-67.

43. Institute for Clinical and Economic Review. Disease-modifying therapies for relapsing-remitting and primary-progressive multiple sclerosis: effectiveness and value. Final evidence report. March 6, 2017. https://icer-review.org/wp-content/uploads/ 2016/08/CTAF_MS_Final_Report_030617.pdf. Accessed May 2017.

44. Merkel B, Butzkueven H, Traboulsee AL, Havrdova E, Kalincik T. Timing of high-efficacy therapy in relapsing-remitting multiple sclerosis: a systematic review. Autoimmun Rev. 2017;16:658-65.

45. Trojano M, Tintore M, Montalban X, et al. Treatment decisions in multiple sclerosis-insights from real-world observational studies. Nat Rev Neurol. 2017;13:105-18. 